\title{
TESTE DE ENVELHECIMENTO PRECOCE PARA SEMENTES DE AZEVÉM, AVEIA PRETA E MILHETO
}

\author{
ACCELERATED AGING TEST FOR RYEGRASS BLACK \\ OAT GRASS AND PEARL MILLET SEEDS
}

\author{
Danton Camacho Garcia ${ }^{1}$ Nilson Lemos de Menezes ${ }^{2}$
}

\section{RESUMO}

A viabilidade da aplicação e da padronização do teste de envelhecimento precoce em sementes de azevém, aveia preta e milheto foi verificada em três lotes, para cada espécie, com valores iniciais de germinação semelhantes. As sementes de cada lote foram submetidas ao teste por períodos de 24, 48, 72 96 e 120 horas, à temperatura de $41^{\circ} \mathrm{C}$ e $100 \%$ de umidade relativa do ar. Em aveia preta, o período de 24 horas estratifica lotes de sementes pelo vigor. Para milheto e azevém, o período de envelhecimento para estratificar lotes de sementes pelo vigor pode ser de 24 a 48 horas. Períodos de 72 a 120 horas são muito drásticos para as três espécies e impedem a estratificação de lotes de sementes pelo vigor.

Palavras-chave: teste de vigor, Lolium multiflorum, Avena strigosa, Pennisetum glaucum.

\section{SUMMARY}

Accelerated aging test standardization for seeds of ryegrass, black oat grass and pearl millet was cheked in three lots, of each specie, with similar initial values of germination. The seeds of each lot were submited to periods of 24, 48, 96 and 120 hours of temperature of $41^{\circ} \mathrm{C}$ and air relative humidity of $100 \%$. In black oat grass the $24 \mathrm{~h}$ period stratifies seed vigor among lots. However, for pearl millet and ryegrass the period can be of 24 to 48h. Periods of 72 to 120 hours are very severe to the three species and prevent the seed vigor lots stratification.

Key words: vigor test, Lolium multiflorum, Avena strigosa, Pennisetum glaucum.

\section{INTRODUÇÃO}

Durante os últimos anos, tem-se evidenciado a necessidade de se obter uma eficiente produ- ção de sementes de espécies forrageiras, como consequiência da demanda para incrementar a área de pastagens cultivadas na região Sul do Brasil. Espécies como azevém, aveia preta e milheto têm demonstrado potencial para produção de sementes, entretanto, problemas estruturais, basicamente de organização comercial, fazem com que essa alternativa ainda se constitua numa expectativa em nível de produtor. Também, as sementes destas espécies, por apresentar um alto valor comercial, merecem maior atenção em relação a sua qualidade fisiológica.

As Normas e Padrões de Produção de Sementes para o Estado do Rio Grande do Sul (SAA/RS, 1997) definem que a qualidade fisiológica de um lote de sementes a ser comercializado deve ser avaliado através do teste de germinação, o qual é realizado em condições ótimas para as sementes, permitindo a manifestação do máximo potencial de germinação das mesmas. Porém, este teste nem sempre revela diferenças na qualidade fisiológica dos lotes, que podem se manifestar durante o armazenamento ou nas condições adversas do campo (MARCOS FILHO, 1981).

Consideradas insuficientes as informações obtidas pelo teste de germinação, os tecnologistas de sementes passaram a estudar o vigor como uma característica capaz de fornecer dados complementares sobre qualidade de sementes. Dentre os inúmeros testes de vigor usados na atualidade, um que vem sendo utilizado com grande freqüência nos Estados Unidos (HAMPTON, 1992) e no Brasil (KRZYZANOWSKI et al., 1991) é o teste de enve-

\footnotetext{
${ }^{1}$ Engenheiro Agrônomo, Aluno do Curso de Pós-graduação em Ciência e Tecnologia de Sementes, Faculdade Eliseu Maciel, Universidade Federal de Pelotas, Pelotas, RS.

${ }^{2}$ Engenheiro Agrônomo, Doutor, Professor Adjunto, Departamento de Fitotecnia, Centro de Ciências Rurais, Universidade Federal de Santa Maria, 97119-900, Santa Maria, RS. Autor para correspondência. 
lhecimento precoce, tendo se tornado hoje um dos mais utilizados para avaliar a qualidade fisiológica das sementes (NASCIMENTO et al., 1993). É um teste de grande utilidade prática, na rotina dos laboratórios, embora apresente ainda, dificuldades na uniformização da sua metodologia (IRIGON \& ROSSINI, 1992). Várias são as causas que concorrem para a desuniformidade dos resultados, dentre elas, o grau inicial de umidade das sementes, pois os efeitos do envelhecimento precoce são atenuados em sementes com baixo percentual de umidade, dificuldade de manutenção da umidade relativa dentro da câmara de envelhecimento, espécie e cultivar utilizados, tempo e temperatura de exposição (MELLO \& TILLMANN, 1987).

O teste de envelhecimento precoce consiste em submeter as sementes a condições adversas de altas temperatura $\left(40-45^{\circ} \mathrm{C}\right)$ e umidade relativa do ar $(100 \%)$, durante um período de tempo e, a seguir, avaliar a resposta através do teste de germinação. Esse teste foi desenvolvido para predizer o potencial de armazenamento de lotes de sementes (DELOUCHE \& BASKIN, 1973).

O objetivo do presente trabalho foi determinar as condições de temperatura e umidade adequadas para avaliação da qualidade de lotes de sementes de azevém, aveia preta e milheto, pelo teste de envelhecimento precoce.

\section{MATERIAL E MÉTODOS}

O experimento foi conduzido no Laboratório de Análise de Sementes de Produção (LASP), no Departamento de Fitotecnia do Centro de Ciências Rurais, da Universidade Federal de Santa Maria.

Utilizaram-se três lotes distintos das seguintes espécies: azevém (Lollium multiflorum L.), aveia preta (Avena strigosa L.) e milheto (Pennisetum glaucum (L.) R.Br.). Todos os lotes foram produzidos na safra agrícola 1996/1997 e foram recebidos pelo LASP-UFSM para análises de rotina.

$O$ grau de umidade de cada amostra foi determinado em duas repetições de $5 \mathrm{~g}$ para todos os lotes de cada espécie, utilizando-se estufa a $105^{\circ} \mathrm{C} \pm$ $3^{\circ} \mathrm{C}$ durante 24 horas, sendo calculada por diferença de massa, com base na massa úmida das sementes, conforme as Regras para Análise de Sementes (BRASIL, 1992)

O teste de germinação foi realizado utilizando-se 400 sementes por lote, para cada espécie, divididas em quatro repetições semelhantes.

As sementes de azevém foram semeadas em caixas do tipo "gerbox", sobre papel, enquanto aveia preta e milheto foram semeadas em substrato rolo de papel. As temperaturas usadas durante o teste foram $20^{\circ} \mathrm{C}$ para a aveia preta e a alternância 20 $30^{\circ} \mathrm{C}$, para azevém e milheto. As avaliações foram executadas de acordo com as Regras para Análise de Sementes (BRASIL, 1992), computando-se as porcentagens de plântulas normais para repetições nos períodos de tempo recomendados.

Para cada espécie, os tratamentos constituíram um fatorial $3 \times 6$ formado por três lotes de sementes e seis períodos de tempo de exposição ( 0 , 24, 48, 72, 96 e 120 horas) das sementes na câmara de envelhecimento a $41^{\circ} \mathrm{C}$ de temperatura e $100 \%$ de umidade relativa do ar, conduzido no delineamento experimental inteiramente casualizado, com quatro repetições.

No teste de envelhecimento precoce, utilizaram-se 200 sementes por tratamento, dispostas em uma única camada e distribuídas sobre uma bandeja de tela de alumínio fixada no interior de uma caixa de plástica tipo "gerbox", funcionando como compartimento individual (minicâmara). No interior desta, foram adicionados $40 \mathrm{ml}$ de água destilada e, a seguir, os "gerbox" foram levados para a câmara de envelhecimento tradicional, conforme metodologia recomendada pelo comitê de vigor da AOSA (1983). As sementes permaneceram na câmara, regulada a temperatura constante de $41^{\circ} \mathrm{C}$ e numa saturação de $100 \%$ de umidade relativa do ar, durante os períodos de 24, 48, 72, 96 e 120 horas. Após esses períodos, as sementes foram colocadas para germinar conforme descrito anteriormente, excetuando-se o número de sementes por repetição, que foi de 50 .

Os valores obtidos para germinação em todos os tratamentos, quando submetidos à análise de variância foram transformados em $\operatorname{Arc} \operatorname{Sen}(X)^{1 / 2 \text {, }}$ para normalização da distribuição dos dados. Para análise, utilizou-se o programa de análises estatísticas SANEST (ZONTA et al.,1984).

\section{RESULTADOS E DISCUSSÃO}

A análise de variância, para as três espécies, mostrou efeitos significativos para o fator lote, tempo de exposição e interação significativa entre lotes e tempos de exposição, indicando que o comportamento da germinação variou significativamente conforme cada lote e estes apresentaram um comportamento diferenciado, dependendo do período de exposição estudado.

Foi realizado o desdobramento da interação significativa entre os fatores, através de uma análise de regressão polinomial ajustando-se, para cada lote, dentro de cada espécie, uma equação, conforme mostrado na tabela 1 , que indicou o comportamento da germinação das sementes após os 


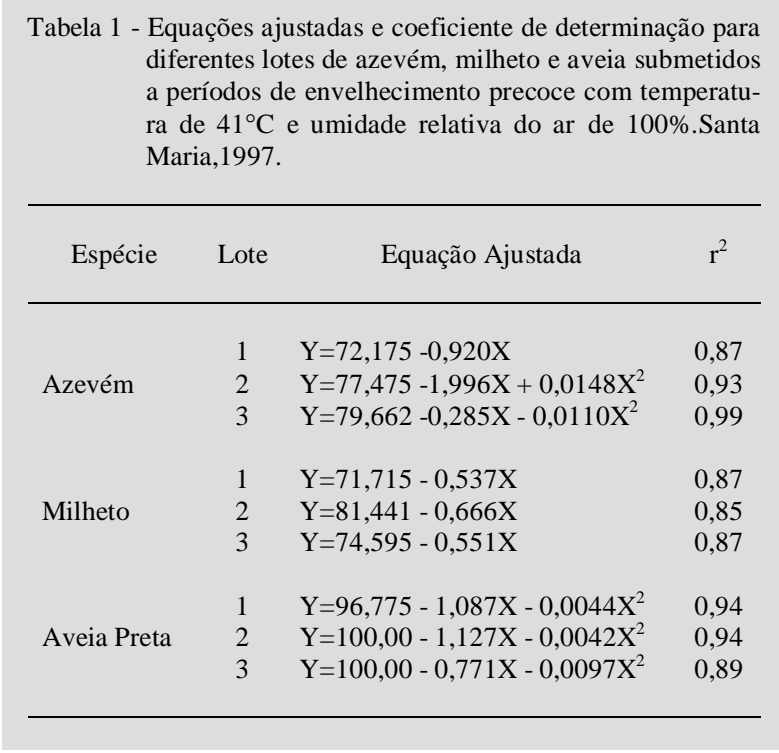

diferentes períodos de envelhecimento precoce, conforme mostrado na figura 1 .

$O$ grau de umidade das sementes foi de $13,1 \%$ para aveia; $12,8 \%$ para azevém e $12,3 \%$ para milheto. Esses níveis de umidade foram adequados para a condução do teste, uma vez que estão na faixa de 11 a $13 \%$, indicada como a mais favorável para a realização do teste (MARCOS FILHO, 1994).

Para todas as espécies e lotes, verificou-se que a germinação das sementes foi reduzida à medida que aumentou o tempo de exposição às condições de estresse provocadas pelo teste de envelhecimento precoce, conforme apresentado na figura 1. Tal comportamento pode ser ajustado por um polinômio do primeiro ou segundo grau com alto coeficiente de determinação, indicando que os modelos matemáticos selecionados mostraram uma boa aproximação do comportamento biológico das sementes durante a execução do teste.

Os resultados apresentados na tabela 2 são provenientes da análise do comportamento da germinação inicial dos lotes, das três espécies dentro de cada período de envelhecimento e da comparação das médias através do teste de Duncan, em nível de $5 \%$ de probabilidade.

A germinação inicial de todos os lotes de azevém e aveia preta, assim como os lotes 1 e 3 de milheto foram estatisticamente semelhantes, com exceção do lote dois em milheto, porém, após os períodos de envelhecimento precoce, ocorreram variações significativas. Isto mostra que o teste de germinação não foi suficientemente adequado para detectar diferenças de vigor entre os lotes, conforme já havia sido observado em diversas espécies por BOUNOUS et $\boldsymbol{a l}$. (1985) e NASCIMENTO $\boldsymbol{e t}$ al. (1993).

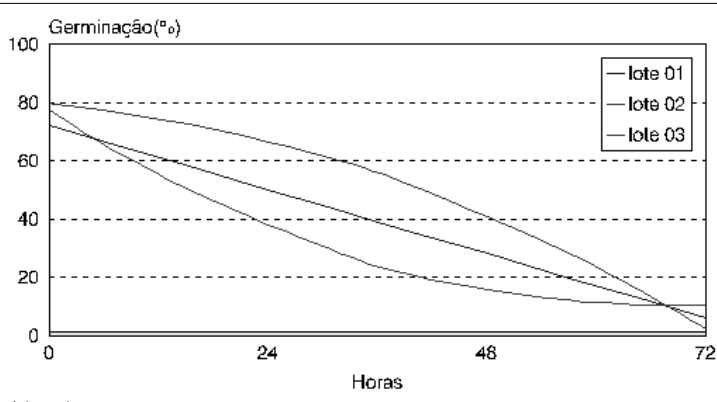

a)Azevém

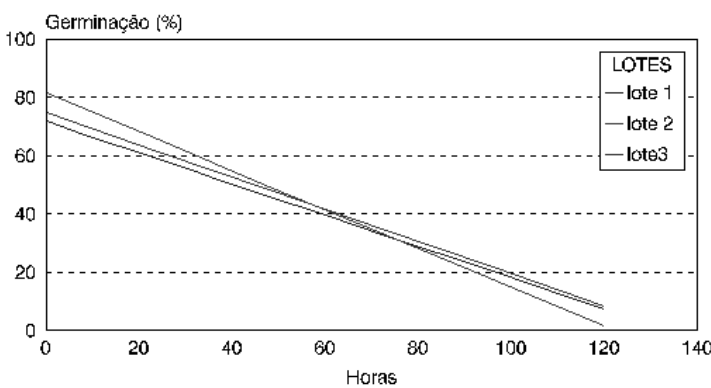

b)Milheto

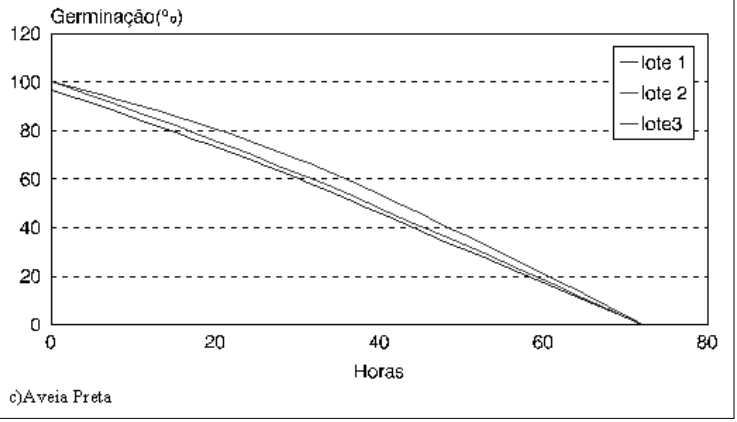

Figura 1 - Germinação de sementes de azevém (a), milheto (b) e aveia preta (c) submetidas a diferentes períodos na Câmara de Envelhecimento Precoce com temperatura de $41^{\circ} \mathrm{C}$ e Umidade Relativa de $100 \%$.

Verificou-se também uma redução progressiva na germinação com o aumento do período de envelhecimento. Após um período de 24 horas, já foi possível observarem-se diferenças de vigor entre lotes nas três espécies. Quanto aos períodos de 96 e 120 horas, para as três espécies, os mesmos não devem ser utilizados, pois mostraram-se muito drásticos às sementes, provocando baixos índices de germinação e não permitindo estratificar os lotes quanto aos níveis de vigor. Na literatura, são relatados resultados com capim colonião (USBERTI, 1982); sorgo (PETRINI et al., 1988); soja (TOMES et al., 1988) e triticale (ROCHA, 1997) para os quais temperaturas de $42^{\circ} \mathrm{C}$ a $45^{\circ} \mathrm{C}$ também se mostraram severas, reduzindo drasticamente o valor da germinação nos tempos de exposição de 72, 96 horas e períodos superiores. 
Tabela 2 - Porcentagem de germinação de lotes de milheto, azevém e aveia preta, submetidos a diferentes períodos de envelhecimento precoce. Santa Maria, 1997.

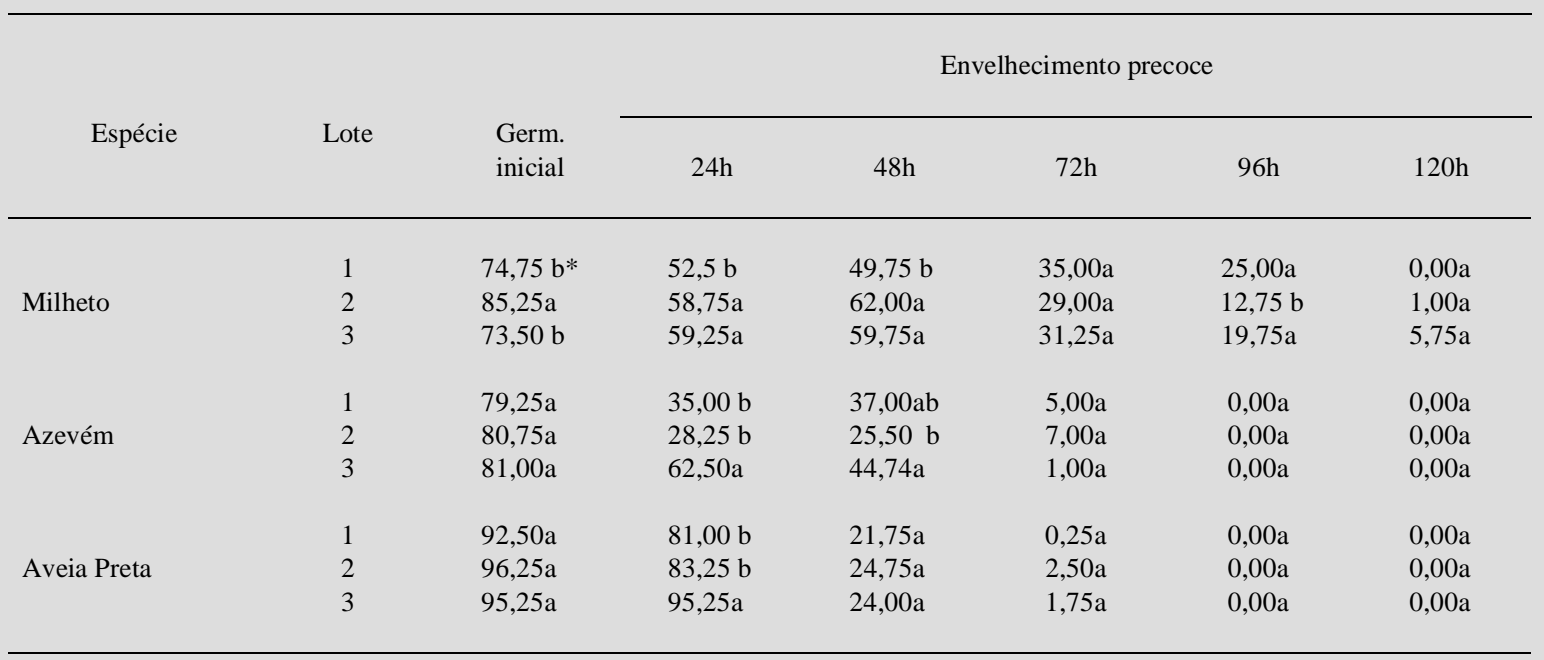

* Médias dos tratamentos, seguidas de mesma letra, em cada coluna, não diferem entre si pelo teste de Duncan $(\alpha=0,05)$.

Em milheto, após o período de 24 horas, foi possível observarem-se diferenças de vigor entre os lotes, seguindo-se de uma tendência semelhante para o período de 48 horas.

Em azevém, pode-se verificar que, para os três lotes, o período de 24 a 48 horas provocou um envelhecimento suficiente para permitir a execução do teste, embora pareça mais conveniente prolongar o teste até 48 horas para garantir a obtenção de uma significativa estratificação entre os lotes. Resultados semelhantes, para esta espécie, foram obtidos nos trabalhos de BOUNOS et al. (1985), BOUNOS (1986) e MAIA (1995).

Dentre as três espécies avaliadas, a aveia preta foi a mais sensível aos períodos de exposição às condições de envelhecimento precoce. Após 24 horas, observaram-se diferenças significativas no vigor. O período de 48 horas ocasionou redução na germinação não se observando a estratificação dos lotes.

\section{CONCLUSÕES}

Mantendo a temperatura a $41^{\circ} \mathrm{C}$ e a umidade relativa em $100 \%$ de UR do ar, o período de 24 horas de estresse no teste de envelhecimento precoce estratifica lotes de sementes de aveia preta pelo vigor. O período de envelhecimento precoce para estratificar lotes de sementes de milheto e azevém pelo vigor deve ser de 24 a 48 horas. Períodos de 72 a 120 horas são muito drásticos para essas três espécies e impedem a estratificação de lotes pelo vigor.

\section{REFERÊNCIAS BIBLIOGRÁFICAS}

ASSOCIATION OF OFFICIAL SEED ANALYSTS-AOSA. Seed Vigour testing Handbook. Lincoln: AOSA, 1983. 93 p. (Contribuition,32)

BRASIL. Ministério da Agricultura e Reforma Agrária. Regras para Análise de Sementes. Brasília: SNDA/DNDV/CLA, 1992. p. 365.

BOUNOUS, E.B., MAIA, M.S., MELLO, V.D.C. Determinação de temperaturas e tempo de exposição para o teste de envelhecimento precoce em azevém. In: CONGRESSO BRASILEIRO DE SEMENTES, 4, 1985. Brasília Resumos.... Brasília, ABRATES, 1985, p. 102

BOUNOUS, E.B. Comparação de métodos de secagem em azevém anual. Pelotas, 1986. 109 p. Dissertação (Mestrado) Curso de Pós-graduação, Universidade Federal de Pelotas, 1986.

DELOUCHE, J.C., BASKIN, C.C. Accelerated aging techniques for predicting the relative storability of seed lots. Seed Science and Technology, Zürich, v. 1, n. 2, p. 427-452, 1973.

HAMPTON, J.G. Vigour testing within laboratories of the International Seed Testing Association: a survey. Seed Science and Tecnology, Zürich, v. 20, n. 1, p. 199-203, 1992

IRIGON, D.L., ROSSINI, M.C. Aferição de testes de vigor para sementes de trigo. Informativo ABRATES, Londrina, v. 3, n. 1, p. 7-23. 1992.

KRZYZANOWSKI, F.C., FRANÇA NETO, J.B Encontro sobre avanços em tecnologia de sementes. Pelotas: FAEM/UFPel, 1991. . Testes de vigor em sementes: $111 \mathrm{p}$.

MAIA, M.S. Secagem de sementes de azevém anual com ar ambiente forçado. Pelotas, 1995, 108 p. Tese (Doutorado)Universidade Federal de Pelotas, 1995. 
MARCOS FILHO, J. Qualidade fisiológica de sementes de soja. Pesquisa Agropecuária Brasileira, Brasília, v. 16, n. 3, p. 405-15, 1981.

MARCOS FILHO, J. Teste de envelhecimento acelerado. In: VIEIRA, R.D., CARVALHO, N.M. Testes de vigor em sementes. Jaboticabal: FUNEP, 1994, p. 133-149.

MELLO, V.D.C., TILLMANN, M.A.A. O teste de vigor em câmara de envelhecimento precoce. Revista Brasileira de Sementes, Brasília, v. 9, n. 2, p. 93-102, 1987.

NASCIMENTO, N.M., BARROS, B.C.G. de, PESSOA, H.B.S.V. Teste de envelhecimento acelerado em sementes de tomate. Revista Brasileira de Sementes, Brasília, v. 15, n. 2, p. 251253, 1993.

PETRINI, J.A., FERNANDEZ, D., ZONTA, E.P. Testes de vigor para predizer a emergência de sorgo. Pesquisa Agropecuária Brasileira, Brasília, v. 23, n. 6, p. 593-598,1988.
ROCHA, J.A.G. da. Teste de Envelhecimento Precoce para Sementes de Triticale. Pelotas, 1997, 10 p. Dissertação (Mestrado) - FAEM, Universidade Federal de Pelotas, 1997.

SECRETARIA DA AGRICULTURA E ABASTECIMENTO DO RIO GRANDE DO SUL - SAA/RS. Departamento de Produção Vegetal. CESM/RS. Normas e padrões de produção de sementes para o Estado do Rio Grande do Sul. Porto Alegre, $1997,140 \mathrm{p}$.

TOMES, L.J., TEKRONY, D.M., EGLI, D.B. Factors influencing the tray accelerated aging test for soybean seed. Journal of Seed Technology, Lansing, v. 12, n. 1, p. 24-36, 1988.

USBERTI, R. Teste de envelhecimento acelerado em sementes de capim colonião. Revista Brasileira de Sementes, Brasília, v. 4, n. 1, p. 23-30, 1982

ZONTA, E.P., MACHADO, A.A. Sistema de análise estatística para microcomputadores (SANEST). Pelotas: UFPel. 1984.

Ciência Rural, v. 29, n. 2, 1999. 